\title{
ESTUDOS
}

\section{A prática educacional do pedagogo em espaços formais e não-formais}

\begin{abstract}
Maria Marina Dias Cavalcante
Eveline Andrade Ferreira

Isabel Magda Said Pierre Carneiro

Resumo

Discute a reformulação do Curso de Pedagogia a partir de análises acerca da constituição identitária do profissional pedagogo e de suas possibilidades de inserção no mercado de trabalho. Para tanto, foram realizadas entrevistas semi-estruturadas com 52 alunos e 47 egressos do Curso de Pedagogia da UECE e com representantes de sete empresas que admitem pedagogos em seus quadros funcionais. Os resultados apontam novas possibilidades de atuação para o pedagogo, assim como dificuldades comuns à docência a ao trabalho na empresa capitalista. Conclui-se que o delineamento preciso do campo de atuação do pedagogo demanda um aprofundamento da discussão nas IES, considerando as experiências em ambientes escolares e não-escolares, assim como as determinações advindas de legislação específica.
\end{abstract}

Palavras-chave: pedagogia; formação profissional; pedagogo.

\section{Abstract \\ The education specialists practice in formal and informal fields}

This work aims to discuss curriculum renovation in the Education course by analysing professional identity and their possibilities of getting a job. Therefore, semi-structured interviews were performed with 52 students, 47 professionals graduated at UECE and seven representatives of companies, which have education specialists in their staff. The results showed new possibilities of acting for professionals in education, as well as difficulties common to teaching and working in capitalist companies. One concluded that a precise evaluation of field, in which educationalists are working, needs profound discussion within the university, considering experiences in schools and in companies, as well as determinations from specific legislation.

Keywords: education specialists training; education course; education specialists in companies. 


\section{Introdução}

Este trabalho apresenta achados da pesquisa Profissão Pedagogo, ${ }^{1}$ desenvolvida no âmbito do Grupo de Pesquisa em Política Educacional, Docência e Memória, do Centro de Educação da Universidade Estadual do Ceará (UECE). O estudo tem por objetivo reunir elementos que possam contribuir para a discussão acerca do processo de reformulação curricular do Curso de Pedagogia na referida instituição (UECE, 2001).

As análises aqui registradas pretendem oferecer subsídios para a discussão acerca da constituição identitária do profissional pedagogo e das suas possibilidades de inserção no mercado, a partir de aspectos destacados em entrevistas com alunos e egressos do Curso de Pedagogia e de representantes de empresas que admitem pedagogos em seu quadro funcional.

A pertinência desta discussão ancora-se nas necessidades ditadas pelas transformações da sociedade que requer mudanças nas formas de organização da produção, do trabalho e nas relações profissionais. Inserido neste cenário, um outro fator justifica um olhar mais atento para o Curso de Pedagogia: as mudanças ocorridas têm afetado a todos os trabalhadores, inclusive o pedagogo, que vem sofrendo o impacto de medidas governamentais voltadas para os profissionais do magistério, resultantes da legislação federal aprovada a partir da década de 1990 (entre as principais: a Lei $\mathrm{n}^{\circ}$ 9.394/96 (de Diretrizes e Bases da Educação Nacional), a Lei $\mathrm{n}^{\mathrm{o}}$ 9.424/96 (que dispõe sobre o Fundo de Manutenção e Desenvolvimento do Ensino Fundamental e de Valorização do Magistério), os Decretos $n^{0} 3.276 / 1999$ e $n^{0}$ 3.554/2000 e as Resoluções CNE/CP n ${ }^{\circ} 01 /$ 2002 e CNE/CP n ${ }^{\circ}$ 01/2006).

Este quadro é reforçado pelas discussões que se estabelecem na literatura nacional e internacional em torno das condições de formação e trabalho dos educadores. Kuenzer (1999, p. 182) alerta para uma concepção de professor que vem se desenhando a partir de um quadro no qual "qualquer um pode ser professor, desde que domine meia dúzia de técnicas pedagógicas”. Comenta, ainda, que esta situação tem resultado na destruição da

[...] possibilidade de construção de um professor qualificado para atender às novas demandas, o que justifica baixos salários, condições precárias de trabalho e ausência de políticas de formação continuada articuladas a planos de carreira que valorizem o esforço e a competência.

Acrescenta, finalmente, que as atuais políticas de formação "apontam para a construção da identidade de um professor sobrante".

Considerando o movimento em torno do Curso de Pedagogia e as inquietações oriundas do debate atual, este trabalho apresenta-se como um esforço de aprofundamento das questões levantadas pela pesquisa antes mencionada. Para uma melhor compreensão do significado institucional dessa iniciativa, cabe fazer algumas considerações sobre o processo de investigação.

\section{Alguns elementos do percurso metodológico}

A proposta de coleta, organização e análise dos dados fundamenta-se na idéia do projeto coletivo de pesquisa como uma alternativa de elevado potencial para o desenvolvimento do trabalho docente e discente no âmbito universitário. Segundo Vieira (2000, p. 24-25),

A proposta da pesquisa em sala de aula constitui uma possibilidade concreta de produção de saber capaz de envolver professores e alunos em empreendimentos coletivos de investigação, com efeitos surpreendentes sobre o processo de ensino-aprendizagem e sobre a dinâmica de seu cotidiano.

A iniciativa envolveu alunos de graduação, sob a orientação de seus professores, ${ }^{2}$ no âmbito das disciplinas Pesquisa Educacional, Planejamento Educacional, Educação Especial e Prática de Ensino.

O estudo contou com informações obtidas através de entrevistas semiestruturadas realizadas com 52 alunos e 47 egressos do Curso de Pedagogia e com representantes de sete empresas que admitem pedagogos em seus quadros funcionais. Ele contempla aspectos do trabalho exercido por alunos e egressos do Curso de Pedagogia, apontando dados sobre as áreas em que estão atuando, a função 
desempenhada, a remuneração, além da percepção acerca da experiência que estão tendo e do mercado de trabalho para o pedagogo. Trata também da compreensão dos representantes de empresas em relação à atuação dos pedagogos na instituição, contemplando questões como: quantidade de pedagogos existente, remuneração, funções assumidas, competências ${ }^{3}$ esperadas para o desempenho de suas funções, lacunas identificadas na formação, além de sugestões para a formação do pedagogo.

Feitas estas considerações, cabe explicitar e discutir no tópico a seguir os achados da investigação.

\section{O trabalho do pedagogo na visão de alunos e egressos}

A respeito da atuação profissional, os dados revelam uma quantidade significativa de entrevistados trabalhando na área educacional (63\%). O fato de a maioria (61\%) possuir vínculo empregatício constitui um dado relevante, considerando o atual processo de proletarização a que o trabalho docente tem sido submetido (Contreras, 2002).

Em relação aos dados referentes à natureza da instituição onde trabalha, percebe-se que parte significativa dos entrevistados pertence a instituições de caráter privado (47\%), conforme revela o Gráfico 1.

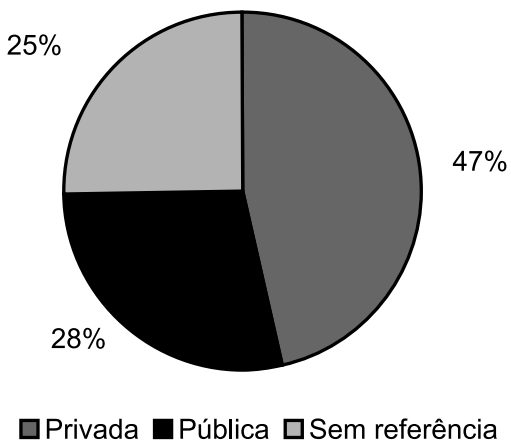

Gráfico 1 - Natureza da instituição, alunos e egressos do curso de pedagogia

Alguns estudiosos afirmam que a justificativa para esta maior concentração de profissionais no setor privado pode estar associada ao fato de o Estado não ter priorizado o ensino público, "permitindo que o setor privado ampliasse a sua participação" (Leite, 1986, p. 122) e, conseqüentemente, sua demanda por profissionais da área. Além disso, a década de 90 assistiu à multiplicação vertiginosa de novas formas de organização não-estatais, como as organizações não-governamentais sem fins lucrativos (conhecidas como ONGs), vinculadas ao chamado Terceiro Setor, que impulsionam a prática educacional em espaços não-escolares demandando a participação de profissionais especializados.

No que diz respeito à função desempenhada, observa-se que, entre os pedagogos e estudantes entrevistados, predomina a função de "professor" (45\%), sendo representativo o número de entrevistados que trabalham em núcleo gestor de escola (22\%). É relevante destacar ainda que $3 \%$ dos entrevistados afirmaram que atuam no campo de recursos humanos, apontando, assim, para a questão acerca das novas funções assumidas pelo pedagogo na sociedade.

O elevado porcentual de pedagogos que trabalham como professores reafirma a perspectiva das Diretrizes Curriculares Nacionais para o Curso de Pedagogia (Parecer $\mathrm{CNE} / \mathrm{CP} \mathrm{n}^{\mathrm{o}}$ 05/2005), quando determinam que

O Curso de Licenciatura em Pedagogia destina-se à formação de professores para exercer funções de magistério na Educação Infantil e nos anos iniciais do Ensino Fundamental, nos cursos de Ensino Médio, na modalidade Normal, de Educação profissional na área de serviços e apoio escolar e em outras áreas nas quais sejam previstos conhecimentos pedagógicos.

Ao mesmo tempo, os dados das entrevistas apontam a demanda pela especialização do pedagogo, seja pelo impacto produzido em seu campo de atuação pelas mudanças que se operam no mundo do trabalho, seja pela tradicional oferta, nas Instituições de Ensino Superior (IES), da habilitação em Administração Escolar, herdada desde meados dos anos 80, quando os pareceres elaborados pelo conselheiro Valnir Chagas traziam a questão das habilitações específicas para o cerne das discussões com associações voltadas para a formação dos profissionais da educação.

No tocante à remuneração recebida, a opinião dos entrevistados é marcada por um forte sentimento de insatisfação. A maioria (47\%) dos entrevistados afirmou 
que recebe entre um e três salários mínimos mensais ${ }^{4}$ (s.m.). Além destes, $15 \%$ revelam que recebem entre quatro e seis s.m., e um reduzido número (5\%) percebe entre sete e nove s.m.

Registra-se um consenso entre alunos e egressos do Curso de Pedagogia, o de que a remuneração é injusta e desvalorizada diante da importância do trabalho do pedagogo, como ilustra o seguinte depoimento: "melhora-se o salário dos juízes, médicos, advogados etc., visando, sobretudo, um melhor estímulo à profissão, e esquecem de que quem forma todos esses profissionais são os professores, pedagogos em potencial" (Aluno $n^{\circ} 12$ ).

Não é novidade que a história dos profissionais da educação (principalmente dos que atuam nos anos iniciais da educação básica) é marcada pela desvalorização. Acerca desta compreensão e dos dados revelados por estudos, Gatti (1997, p. 59) comenta que essa situação desprestigiada deve-se a vários fatores, entre eles "as condições de formação oferecidas pelos cursos em si, as condições em que seu exercício se dá e pelas condições salariais".

Em contrapartida, os discursos sobre a valorização do magistério têm aumentado nos últimos tempos, sobretudo no decorrer das décadas de 80 e 90; esta última, inclusive, instituída como "década da educação” na Conferência Mundial de Educação para Todos (Jontiem, 1990). Esta preocupação tem se manifestado na retórica governista, mas infelizmente a falta de políticas que resultem em mudanças significativas persiste até os dias atuais.

O mais breve olhar sobre a história educacional no Brasil leva o observador a perceber que nos anos 40 e 50 a figura do educador era bastante respeitada, pois lhe era atribuído um certo status social no qual prevalecia a idéia de saber, abnegação e vocação (Ranjard, 1984). Nesse contexto, o conceito de professor aproximava-se do conceito de santo - o que pressupõe, sem dúvida, algum sacrifício (Ferreira, 1998). Porém, a partir dos anos 60, o status inerente à imagem social do professor começa a perder a nitidez; a almejada melhoria das condições de trabalho e de salário passa a se constituir como pressuposto para redefinir o status social do mestre. Dessa forma, tanto para os professores como para qualquer outra classe profissional, o salário assume o papel de um "forte elemento da crise de identidade que os afeta" (Esteve, 1999, p. 34).

Em especial na situação do professor, a crise de identidade profissional está associada a uma política de desvalorização que o considera como um mero técnico reprodutor de conhecimentos, um profissional desqualificado, um "semiprofissional" (Sarmento, 1994, p. 39). Além disso, a "crescente desprofissionalização do docente" pode ser interpretada também como conseqüência dos baixos salários, articulados ao “déficit de professores, em algumas regiões, facilitando o ingresso de profissionais de outras áreas para exercer a docência” (Pinto, 1998, p. 343).

Mesmo diante de uma situação em que o campo de atuação é impreciso e a remuneração não é satisfatória, as experiências de trabalho vivenciadas são consideradas positivas e enriquecedoras pela maioria de entrevistados (73\%), destacada no Gráfico 2.
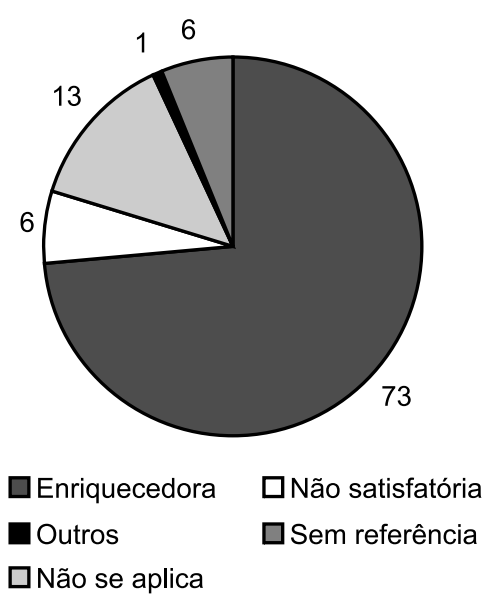

\section{Gráfico 2 - Experiência de trabalho}

Muitos mencionam a satisfação com a experiência de trabalho associada à possibilidade de "contribuir para a melhoria da educação”. É o que ilustra o depoimento abaixo:

A cada dia me sinto gratificado em saber que posso ajudar as crianças a ter uma perspectiva melhor. Apesar das adversidades, nós professores temos um papel importante na luta contra as desigualdades sociais, e somente através da educação conseguiremos formar uma sociedade mais justa e solidária (Aluno $\mathrm{n}^{\mathrm{O}} 12$ ). 
A compreensão que os estudantes têm do trabalho educativo na sociedade enfatiza, por vezes, a transformação da realidade e a formação do cidadão. Essa perspectiva pode indicar que o Curso de Pedagogia tem produzido algum impacto na formação da competência política dos estudantes, ao mesmo tempo em que aponta a urgência de despertar o profissional em formação para o engajamento na luta cotidiana por melhores condições de vida e de ensino. A formação universitária não deve se restringir à competência técnica, e sim abranger uma dimensão mais ampla e humana, desenvolvendo nos estudantes a sensibilidade para as questões políticas, históricas e sociais, e munindo-os, inclusive, de uma compreensão mais consistente e fundamentada.

É preciso que o futuro profissional saia da Universidade ciente das peculiaridades sócio-culturais, políticas e econômicas de sua sociedade, e convicto de que sua intervenção no social precisa ter sempre um vetor de transformação dos vínculos que fazem com que essa sociedade não consiga ser uma sociedade democrática, ou seja, uma sociedade mais justa, mais eqüitativa e mais humana (Severino, 2000, p. 186).

Contraposta à concepção que os entrevistados têm da importância do trabalho pedagógico realizado, é corrente uma visão negativa sobre o mercado de trabalho do pedagogo. A maioria considera difícil conquistar seu espaço de atuação. O Gráfico 3 revela essa questão.

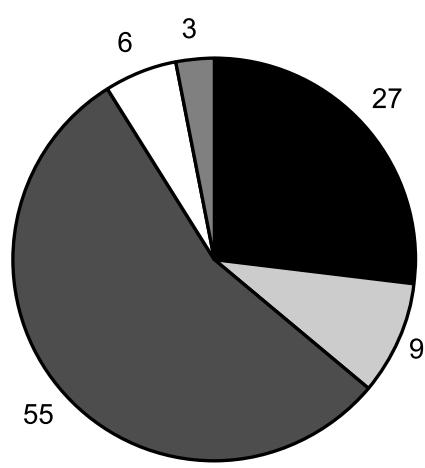
Amplo
口Em crescimento
$\square$ Restrito/desvalorizado $\square$ Outros $\square$ Sem referência

\section{Gráfico 3 - Visão do mercado de trabalho}

É interessante destacar que uma das razões para os entrevistados considerarem o mercado restrito e desvalorizado é a invasão de outros profissionais no campo do pedagogo: "a incidência de outros profissionais acaba ocupando o espaço que nos é reservado" (Egresso n ${ }^{0} 22$ ).

A entrada de outros profissionais para o exercício da docência remete à questão da crise de identidade não só do Curso de Pedagogia, mas também de outras licenciaturas, cuja discussão envolve, necessariamente, o campo de trabalho do professor. Assim, entre outros aspectos, um dos agravantes do processo de fragilização desta profissão

[...] é a inexistência de um conselho federal e regional que se empenhe em assegurar benefícios, espaços profissionais e, principalmente, a regulamentação do exercício da profissão por trabalhadores efetivamente habilitados, como é o caso da OAB, Crea e ABO (Veiga, 2001, p. 30).

Essa questão acaba interferindo de certa forma na definição do locus de formação dos profissionais da educação, a partir dos dispositivos legais. O art. 62 da Lei $n^{\circ}$ 9.394/ 96 determina que a universidade deve compartilhar com os Institutos Superiores de Educação (ISE) a responsabilidade de formar professores. Entretanto, esta instância de formação de professores assume, na verdade, além de outras funções, aquela competente aos cursos de Pedagogia - a formação de licenciados para atuar na educação infantil e nas primeiras séries do ensino fundamental -, gerando discussões ferrenhas acerca das conseqüências de uma formação oferecida distante dos princípios universitários de ensino, pesquisa e extensão.

Além destes, novos elementos trazem à tona a discussão sobre a função e a formação do pedagogo habilitado para atuar em áreas específicas, pois, de acordo com a Lei no ${ }^{\circ}$ 9.394/96, "a formação de profissionais de educação para administração, planejamento, inspeção, supervisão e orientação educacional para a educação básica será feita em cursos de graduação em Pedagogia ou em nível de pós-graduação" (art. 64). Essa discussão toma impulso na emenda proposta na Resolução CNE/ CP 01/2006, quando determina que "esta formação profissional também poderá ser realizada em cursos de pós-graduação, 
especialmente estruturados para este fim e abertos a todos os licenciados". É necessário reconhecer - mas difícil dimensionar - o impacto destas prerrogativas sobre a (in)definição do Curso de Pedagogia.

As funções do Curso de Pedagogia são bastante abrangentes, e este fato certamente se articula aos depoimentos de entrevistados que vêem o mercado de trabalho do pedagogo "em crescimento" (9\%), devido ao "reconhecimento que se tem procurado dar à educação como via de melhoramento da situação atual do País” ou, ainda, "amplo" (27\%), destacando que o trabalho do pedagogo pode ser ampliado para outros espaços educativos como registra o seguinte depoimento: "hoje o educador não necessariamente precisa atuar apenas na sala de aula ou em coordenação, mas poderá atuar como orientador em diversas áreas” (Aluno $\mathrm{n}^{0} 19$ ).

O depoimento citado caminha no sentido de ressaltar os novos campos de atuação do pedagogo, aspecto que vem sendo discutido por vários segmentos da sociedade. A Comissão de Especialistas de Ensino de Pedagogia (1999), por exemplo, defende o seguinte perfil para o pedagogo:

Um profissional habilitado a atuar no ensino, na organização e gestão de sistemas, unidade e projetos educacionais e na produção e difusão do conhecimento, em diversas áreas da educação, tendo a docência como base obrigatória de sua formação e identidades profissionais.

Contribuindo com esta discussão, Libâneo e Pimenta (2002) enfatizam a importância da formação de profissionais de educação para atuar em contextos escolares e não-escolares. Essa diversidade de atuação demonstra novas perspectivas para o campo de trabalho do pedagogo, já que, historicamente, era concebido apenas como "professor" ou "técnico da educação”. A concepção abrangente do exercício deste profissional abre portas para atuação em outras instituições, inclusive em empresas, aspecto que será discutido no tópico a seguir.

\section{O pedagogo nas empresas}

O debate acerca do reconhecimento da importância da Pedagogia em diversos espaços não-escolares tem se ampliado, principalmente a partir dos anos 1990. A intensidade de tal debate se coloca a partir das transformações sociais, políticas e econômicas que vêm ocorrendo no mundo, impulsionada, principalmente, pelas novas demandas postas pelo que tem sido chamado Revolução da Tecnologia da Informação (Castells, 2000). Esse cenário revela que os avanços na comunicação, na informática e outras mudanças tecnológicas e científicas têm implicado diferentes desafios de atuação e formação para os pedagogos, considerando-se crescente a demanda por intervenções e ações educativas em âmbitos, meios e organizações diferenciadas do sistema educacional. Ademais, a atuação como docentes ou especialistas da educação (direção, supervisão, coordenação e orientação educacional, entre outras atividades específicas da escola) tem-se modificado ao longo do tempo, apontando espaços que extrapolam os "muros das escolas" e das instituições de ensino.

\section{Há que se encontrar respostas para outras circunstâncias emergentes que estão exi- gindo respostas e decisões educativas: a ampliação dos espaços educativos para além dos muros da escola é uma realida- de incontestável; as novas e complexas formas em que se estabelecem as relações de trabalho estão a demandar novos mei- os e espaços de formação de jovens; as conseqüências sociais decorrentes da internacionalização da economia, entre outros fatores, exigem o repensar do papel da pedagogia, a direção da construção de novas mediações sociais e políticas, com vistas a um projeto de futuro digno, às novas gerações (Franco, 2003, p. 14).}

Nesse contexto, buscou-se aqui investigar a atuação do pedagogo que trabalha em empresas. Para isso, foram pesquisadas sete instituições de caráter privado, que admitem pedagogos em seu quadro funcional. No momento da pesquisa, apenas três apresentavam pedagogos contratados (uma empresa, inclusive, com mais de um pedagogo). Achou-se, portanto, relevante ouvir o que pensavam.

Com relação ao tempo de exercício da profissão, observa-se que a maior parte dos pedagogos está lotada em empresas há menos de quatro anos. Em apenas uma instituição foi constatada a existência de um funcionário com formação em Pedagogia, atuando há mais de 15 anos. 
Os dados sobre as funções assumidas pelos pedagogos na empresa foram marcados pela diversidade manifesta no discurso das respostas. Percebeu-se que nem sempre a atuação desse pedagogo é condizente com a formação recebida. Foram mencionadas as atividades exercidas na área de benefícios, de treinamento de funcionários (em especial de telecursos) e recepção.

Os representantes de empresas afirmaram que, muitas vezes, os pedagogos contratados exercem funções que não correspondem à sua formação. Alguns estudos, como o de Macedo (1998) acerca do pedagogo na área de recursos humanos, constatam que o fato de esta ser uma área multidisciplinar, envolver conhecimentos de psicologia do trabalho, sociologia organizacional, direitos trabalhistas, engenharia do trabalho, serviço social, etc., torna difícil saber "qual formação específica é a mais apropriada para o profissional de recursos humanos" (p. 21). Isto acaba por causar uma indefinição do perfil do funcionário responsável pela área de recursos humanos, resultando na possibilidade de contratação de diversos profissionais, inclusive de pedagogos.

Esse caráter multidisciplinar no contexto empresarial é um aspecto relevante do trabalho assumido pelo pedagogo na empresa, pois exige a racionalidade de múltiplos olhares sobre as situações vivenciadas na sua intervenção pedagógica, identificando e interpretando as diversas facetas que se apresentam no seu cotidiano (Therrien, 2006).

Outro ponto fundamental para esta reflexão foi a perspectiva de salário. Buscou-se perceber se há diferença em relação à remuneração recebida por outros pedagogos que exercem funções escolares. A partir da fala dos entrevistados, constatou-se que a remuneração varia de acordo com a empresa, predominando, neste estudo, a faixa salarial que ultrapassa os sete salários mínimos, fato comentado no seguinte depoimento: "o pedagogo entra no quadro normal de funcionários e recebe gratificação de acordo com a função, não havendo remuneração diferenciada para profissionais de outras áreas" (Depoimento $\left.\mathrm{n}^{\mathrm{O}} 4\right)$.

Quando indagados sobre as competências esperadas para o profissional de Pedagogia que atua em empresas, as respostas voltaram-se para atividades de planejamento e de elaboração de projetos, com destaque para a demanda por profissionais "criativos", capazes de assessorar a administração da empresa, e, sobretudo, com capacidade para "transmitir conhecimentos".

No âmbito das transformações do mundo contemporâneo, há uma nítida mudança nos modos de pensar, agir e interagir que influencia o desempenho do pedagogo em seu trabalho, suscitando a definição de um profissional preparado para atender as diversas possibilidades educativas da sociedade.

As novas demandas educacionais requerem um pedagogo capaz de exercer seu trabalho em correspondência às novas realidades da sociedade, do conhecimento, dos educandos, bem como dos meios de comunicação e informação. Esse apelo das competências no mundo do trabalho e da vida exige, portanto, um conjunto de conhecimentos, habilidades, procedimentos e técnicas que o pedagogo mobiliza para elaborar um diagnóstico rápido da situação de seu trabalho, desenhar estratégias de intervenção e prever o curso futuro dos acontecimentos (Market, 2004).

A maioria dos entrevistados reconhece, ainda, a existência de competências próprias do pedagogo que atua em empresas, mas a falta de preparação para atuar nessas instituições fica nítida quando são apontadas as lacunas existentes na atual formação do pedagogo, situando entre elas a ausência de compreensão do contexto empresarial e a ausência de disciplinas e estágios para treinamento.

A desvinculação dos conteúdos dos cursos de Pedagogia com o contexto empresarial é discutida por Macedo (1998), ao confirmar a importância da Pedagogia como teoria geral da educação, inclusive no campo empresarial, mas ressaltando a falta de sintonia entre as universidades no tocante à reformulação dos currículos de modo a atender à demanda das empresas. Os entrevistados representantes de empresas sugeriram novas áreas para atuação do profissional formado em Pedagogia, sendo possível perceber que a opinião se volta para a oportunidade de o pedagogo atuar em contextos distantes do tradicional modelo de educação escolar, como, por exemplo, ocupando departamentos de consultoria e treinamento em empresas:

Buscar possíveis espaços dentro das empresas e mudar essa visão; acho que

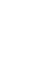

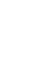


depende muito mais do Pedagogo do que das empresas em si. Na medida em que o Pedagogo enxergar que pode ter uma contribuição diferente da contribuição que ele já dá dentro da sala de aula, com certeza esses espaços vão aparecer (Depoimento $\mathrm{n}^{0} 5$ ).

Os entrevistados também fazem sugestões com relação às competências que precisam ser reforçadas na formação do pedagogo, como "o trabalho com a educação de jovens e adultos, divulgação de projetos da área educacional, além de elaboração de material didático", o que parece bastante pertinente com o contexto investigado.

A Resolução CNE/CP 01/2006 Diretrizes Curriculares Nacionais para o Curso de Graduação em Pedagogia procura contemplar essas sugestões que determinam a formação do profissional para "exercer funções de magistério na Educação Infantil, nos anos iniciais do Ensino Fundamental e na organização e gestão de sistemas e instituições" (art. $4^{\circ}$ ). Entretanto, rompe o desafio ao egresso do Curso de Pedagogia: iniciar sua carreira com a possibilidade de atuar nesses três campos específicos de saberes que dão suporte à sua práxis.

Como o perfil do profissional de Pedagogia traçado pelas Diretrizes apresenta um amplo conceito de docência, observa a gestão dos processos educacionais e a produção e difusão do conhecimento científico e tecnológico no campo educacional, as competências sugeridas pelos entrevistados também foram consideradas pelos legisladores.

Vale ressaltar que a educação para jovens e adultos a que os entrevistados se referem volta-se para a possibilidade de formação e qualificação de funcionários no âmbito da própria empresa, diferentemente dos padrões escolares vigentes.

É possível constatar uma excessiva preocupação por parte dos entrevistados com uma formação inicial de pedagogos voltada para atender às exigências do trabalho desenvolvido em empresas. No entanto, é necessário considerar dois aspectos. O primeiro é que, apesar da carência de conhecimentos específicos para a atuação do pedagogo em espaços não escolares, novas experiências universitárias têm se configurado na busca de desvelar os campos de atuação que ora despontam (respaldadas, agora, por legislação específica) (Olinda, 2003; Ceccim, 1997). O segundo aspecto - não menos relevante - é a existência, no Curso de Pedagogia, de um conjunto de conhecimentos advindos de diferentes campos científicos, como Sociologia, Psicologia, Filosofia, Antropologia, História, entre outros, que visam proporcionar uma leitura crítica, reflexiva e transformadora do mundo, capaz de questionar o próprio sentido do serviço à empresa nos moldes capitalistas em que está constituída atualmente.

A formação almejada implica, portanto, a capacidade do pedagogo de realizar leituras interdisciplinares dos fenômenos educacionais, fundamentandose nos múltiplos saberes e conhecimentos acumulados historicamente pela humanidade e priorizando a dimensão ética em seu trabalho.

\section{Considerações finais}

A análise dos resultados das entrevistas revela uma realidade marcada por nítidas contradições. Na condição de profissional preparado prioritariamente para atuar no campo escolar, o pedagogo depara-se com todos os problemas inscritos na realidade do magistério, como os salários reduzidos, além da evidência de um mercado de trabalho restrito e desvalorizado. Então, mesmo reconhecida a importância do profissional pedagogo para a sociedade, percebe-se que as discussões sobre suas condições de trabalho e formação sofrem o acréscimo dos debates sobre uma identidade profissional ainda desfigurada.

Neste quadro, as experiências de trabalho tornam-se enriquecedoras: consolidam os saberes necessários à prática cotidiana, ao mesmo tempo em que legitimam e delineiam o campo de atuação profissional, lançando pistas para novas propostas de configuração dos cursos de formação inicial.

Ultrapassando as questões das condições de trabalho do pedagogo no âmbito escolar e alcançando outro contexto de atuação - a empresa -, percebe-se que os representantes de empresas admitem a existência de competências específicas para o pedagogo, apesar de não conseguirem especificá-las. Os entrevistados reconhecem a necessidade de uma formação que se volte para o contexto empresarial, 
para o planejamento e para a elaboração de projetos, sugerindo que os cursos de Pedagogia contemplem essas questóes de maneira cuidadosa. Destacam, ainda, que a falta de ancoragem da matriz curricular dos cursos de Pedagogia em relação à atuação de pedagogos em empresas repercute nas dificuldades de exercício profissional.

As mudanças no mundo contemporâneo incitam novas formas de organização do trabalho, aumentando a demanda por profissionais da educação em diversos campos. Portanto, ao mesmo tempo em que abrem um leque de possibilidades para a atuação do educador pedagogo, revelam a contradição existente entre a sua função educativa e a possibilidade de "enquadramento" na empresa capitalista. Oferecem nitidez às cores do confronto entre a autonomia - intrínseca a um projeto educativo libertador - e a heteronomia, condição para a sustentação de um sistema capitalista que sobrevive à base dos profissionais "sobrantes".
Os impasses e as perspectivas gerados no atual contexto do Curso de Pedagogia devem despertar para práticas inovadoras que envolvam a formação de educadores para atuar em diversos espaços (escolares e não-escolares). Somente dessa forma é possível dimensionar o impacto dos fatores explícitos (e implícitos) nos discursos de estudantes e egressos do curso de Pedagogia, de representantes de empresas, nas novas configurações de mercado que se estabelecem e nas prerrogativas legais recém-aprovadas sobre a formação e a função do pedagogo na sociedade.

Neste cenário, verifica-se a necessidade de aprofundamento dessa discussão no âmbito das Instituições de Ensino Superior, considerando, além dos debates que ocorrem no cerne dos movimentos organizados de educadores, os elementos lançados pela aprovação das vigentes Diretrizes Curriculares Nacionais para o Curso de Graduação em Pedagogia (Resolução $\mathrm{CNE} / \mathrm{CP}$ 01/2006).

\section{Referências bibliográficas}

BRASIL. Parecer CNE/CP n ${ }^{\circ} 5$ de 13 de Dezembro de 2005. Diretrizes Curriculares Nacionais para os Cursos de Graduação em Pedagogia. Brasília, 2005.

BRASIL. Resolução CNE/CP n ${ }^{\circ} 01$ de 15 de Maio de 2006. Institui Diretrizes Curriculares Nacionais para o Curso de Graduação em Pedagogia, licenciatura. Brasília, 2005.

CASTELLS, M. A sociedade em rede: a era da informação: economia, sociedade e cultura. 3. ed. São Paulo: Paz e Terra, 2000. v. 1.

CECCIM, R. B. et al. Escuta pedagógica à criança hospitalizada. Criança hospitalizada: atenção integral como escuta à vida. Porto Alegre: Ed. UFRGS, 1997.

COMISSÃO DE ESPECIALISTA DE ENSINO DE PEDAGOGIA. Proposta de diretrizes curriculares para o curso de Pedagogia. São Paulo: Unesp, 1999.

CONTRERAS, J. A autonomia dos professores. Tradução de Sandra Trabucco Venezuela. São Paulo: Cortez, 2002.

ESTEVE, J. M. O mal-estar docente: a sala-de-aula e a saúde dos professores. Bauru, SP: Edusc, 1999.

FERREIRA, R. Entre o sagrado e o profano: o lugar social do professor. Rio de Janeiro: Quartet, 1998.

FRANCO, M. A. S. Pedagogia como Ciência da Educação. Campinas, SP: Papirus, 2003.

GATTI, B. A. Formação de professores e carreira: professores e movimentos de renovação. Campinas, SP: Autores Associados, 1997.

KUENZER, A. Z. As políticas de formação: a constituinte da identidade do professor sobrante. Educação e sociedade, Campinas, v. 68, ano XX, 1999. 
LIBÂNEO, J. C.; PIMENTA, S. G. Formação dos profissionais da educação: visão crítica e perspectivas de mudança. In: PIMENTA, S. G. (Org.). Pedagogia e pedagogos: caminhos perspectivas. São Paulo: Cortez, 2002. p. 11-57.

LEITE, S. A. da S. O papel dos “especialistas” na escola pública. Educação e Sociedade, Campinas, v. 22, ano VII, p. 120-131, 1986.

MACEDO, D. C. O pedagogo como profissional de recursos humanos. 1998. Dissertação (Monografia) - Universidade Estadual do Ceará, Fortaleza, 1998.

MARKERT, W. Trabalho e competência: contribuições para a construção crítica de um conceito e para a formação do profissional transformativo.Campinas, SP: Autores Associados, 2004.

OLINDA, E. M. B. de. A construção coletiva de um objeto de estudo a partir da integração entre ensino, pesquisa e extensão. In: MATOS, K. S. L. de (Org.). Movimentos sociais, educação popular e escola: a favor da diversidade. Fortaleza: Editora UFC, 2003. p. 128-143.

PINTO, L. G. de O. Política educacional e o salário do magistério público estadual. In: SERBINO, R. V. et al. Formação de professores. São Paulo: Fundação Ed. Inesp, 1998.

RANJARD, P. Les enseignants persécutés. Paris: Robert Jauze, 1984.

SARMENTO, M. J. A vez e a voz dos professores. Lisboa: Porto, 1994.

SEVERINO, A. J. A nova LDB e a política de formação de professores: um passo à frente e dois atrás... In: FERREIRA, N. S. C.; AGUIAR, M. A. S. (Org.). Gestão da Educação. 3. ed. São Paulo: Cortez, 2000.

THERRIEN, J. De alguns princípios da pedagogia e os impasses na definição desse campo de saber profissional. In: ENCONTRO NACIONAL DE DIDÁTICA E PRÁTICA DE ENSINO -ENDIPE, 13., Recife, 2006. [Anais...] Recife, 2006.

UNIVERSIDADE ESTADUAL DO CEARÁ. Profissão pedagogo. Banco de dados. Grupo de Pesquisa Política Educacional, Docência e Memória. Fortaleza, 2001. Não publicado.

VEIGA, I. P. A. et al. Licenciatura em pedagogia: realidades, incertezas, utopias. Campinas, SP: Papirus, 2001.

VIEIRA, S. L. Formação em Pesquisa - a alternativa de caminhar em grupo. In: CAVALCANTE, M. M.; NUNES, J. B. C.; FARIAS, I. M. S. de (Org.). Pesquisa em educação na UECE: um caminho em construção. Fortaleza: Demócrito Rocha, 2002. p. 17-32.

Maria Marina Dias Cavalcante, doutora em Educação Brasileira pelo Programa de Pós-Graduação da Universidade Federal do Ceará (UFC), é professora adjunta do Centro de Educação da dessa universidade.

marina@uece.br

Eveline Andrade Ferreira, mestre em Educação pela Pontifícia Católica da Universidade de Minas Gerais (PUC-MG), é professora substituta do Departamento de Teoria e Prática do Ensino da Faculdade de Educação da Universidade Federal do Ceará (UFC). evelineaf@yahoo.com.br

Isabel Magda Said Pierre Carneiro é mestranda em Educação Brasileira pelo Programa de Pós-Graduação da Universidade Federal do Ceará (UFC) e bolsista do Conselho Nacional de Desenvolvimento Científico e Tecnológico (CNPq).

isabelmsaid@yahoo.com.br

Recebido em 12 de janeiro de 2006.

Aprovado em 15 de agosto de 2006. 